\title{
Costa acumulativa do Rio Jaboatão ao Cabo de Santo Agostinho/PE - Brasil: Processos Transformadores do Olhar Distraído ao Olhar Dirigido na Eficácia de Produzir Mudanças.
}

\author{
Niédja Maria Galvão Araújo e Oliveira ${ }^{1}$ \\ João Allyson Ribeiro de Carvalho ${ }^{2}$ \\ Lucilene Correia de Luna ${ }^{3}$ \\ Flávio Romero Sousa Spinelli ${ }^{4}$
}

\begin{abstract}
Resumo: Os sistemas geográficos das zonas costeiras têm sofrido grandes modificações devido ao seu alto grau de fragilidade, por sua geodinâmica e por constituir espaço de interfaces. Em particular os costeiros das zonas tropicais. Nesse sentido, a pesquisa tem como objeto a costa acumulativa do setor sul da zona costeira do Estado de Pernambuco, correspondendo ao espaço intersticial entre a Praia de Gaibu e a foz do rio Jaboatão, somado ao seu objetivo de analisar em plano evolutivo o ambiente costeiro de forma que, como objeto dinâmico reflita ambientes acumulativos marinhos, flúvio-marinhos e formas de ocupação do solo, visando identificar os reflexos da ação antrópica no sistema. Para obtenção dos dados realizou-se levantamento bibliográfico, avaliação de imagens cósmicas da área e análise de indicadores ambientais, sociais, culturais e econômicos. Métodos eficazes luminosos que passam a indicar costas acumulativas e praiais a saírem do foco opaco à eficácia de produzir mudanças.
\end{abstract}

Palavras-chave: Geodinâmica; Fragilidade; Gênese Quaternária; Erosão Costeira

\section{Accumulative coast from the Jaboatão River to Cabo de Santo Agostinho/PE - Brasil: A transformation process from the look at to the look into trying to produce changes}

\begin{abstract}
The geographic systems of the coastal zones have suffers big alterations due to its high degree of fragility, By its geodinamic and by it be interfaces spaces. In particular, tropical coastal areas. Accordingly, the research focuses te comulative coast of southern coastal area of Pernambuco state, correspoding to the interstitial space between Gaibu beach and the mouth of the Jaboatão river, added to its goal in analyzing well into flat evolutionary of the rib environment as a dinamic active object that reflects the cumulative atmospheres of marine environments, the fluvial-marine ambient and the land occupation trying to detect the reflections from of the antropic actions in this specifc system. To attain the data. It was done a bibliographical lifting, as a appraisal of cosmic imaging from the Area and analysis of environmental, social, cultural and economics indexes. Clear and effective Expedients are used to denote accumulative coasts and the beachs that exited from the center of opaque attention.
\end{abstract}

keywords: Geodinamic; Fragility; Genesis of Quaternary Quaternary; Coastal Erosion.

\footnotetext{
${ }^{1}$ Universidade de Pernambuco, noliveir@oi.com.br

2 Universidade de Pernambuco, allysondecarvalho@hotmail.com

${ }^{3}$ Universidade de Pernambuco, lucorrial@yahoo.com.br, Bolsista CNPq/FDPE/UPE

${ }^{4}$ Universidade de Pernambuco, flaviospineli@yahoo.com.br, Bolsista PIBIC/CNPq/UPE
} 


\section{INTRODUÇÃO}

Uma parte importante da sociedade humana se concentra nos sistemas costeiros do planeta. A existência da fronteira entre a terra e o mar determina um grande número de elementos que são aceitos sem um questionamento, tais como a quantidade de terra disponível para o estabelecimento direto do homem e a importância da agricultura, a produtividade ecológica dos sistemas costeiros, baías e portos usados para o comércio e outros. As franjas costeiras acumulativas, em particular as holocênicas, são um exemplo claro desse processo histórico-evolutivo ocorrido nos últimos 500 anos no Estado de Pernambuco, no espaço intersticial entre a Praia de Gaibu e o estuário do rio Jaboatão.

A análise geomórfico-ambiental que o estudo se propõe, investe-se de uma preocupação que contempla o meio natural e o socioeconômico em um sistema de relações ao longo dos processos históricos, dos quais resultam da criação de um espaço provável de ordenamento e tomada de medidas. Deve-se destacar também como justificativa a análise dos sistemas produtores das formas acumulativas dominantes, restingas e mangues, indicando um duplo papel de ações: 1 - ordenar para conservar e proteger o meio e para empregar racionalmente os recursos sem romper os naturais e 2 - corrigir os erros, resultado das agressões sofridas pelo ambiente mediante as ações antrópicas, considerando as modificações que afetam a área pesquisada. Importante frisar que não se trata somente da paisagem costeira "natural", mas da paisagem total integrando todas as implicações da ação antrópica e da natureza.

A orla costeira é uma estreita faixa de contato da terra e mar, na qual a ação dos processos costeiros em geral se faz sentir de forma mais acentuada e potencialmente mais crítica, à medida que efeitos erosivos ou deposicionais podem alterar sensivelmente a configuração da linha de costa (MUEHE, 2001). Esta faixa é formada por sedimentos inconsolidados, como as praias, ou por rochas, como as falésias. Seu equilíbrio dinâmico depende diretamente do balanço da constante interação dos fenômenos terrestres e marinhos.

Christofoletti (1980) define costa como um conjunto de formas componentes da paisagem que estabelece uma área de contato, na qual se faz sentir a influência marinha, que pode atuar de forma indireta. A visão do autor sobrepassa o teórico e alcança o real ao se reportar às formas de relevo como indicativo da ação indireta e de ações dos oceanos. A referida visão pode indicar a intervenção do mar na gênese das formas acumulativas de mangues, 
restingas, lagunas e formas menores, que estão influenciadas pela ação marinha, independente de sua gênese. Oliveira (1998) considera que dentro da zona de costa, os sistemas costeiros podem ser lidos como abertos do tipo processos e resposta.

Geologicamente, a área de trabalho está situada no Grupo Pernambuco, mais especificamente na Formação Cabo. Tal formação foi considerada primeiramente por Cobra (1960), argumentando ser o pacote uma formação complexa e constituída de material conglomerático, sendo tal formação depositada sobre material de origem vulcânica.

Manso et al. (1992) afirma que em função da complexidade do ambiente, podem-se distinguir diversos subcompartimentos geomorfológicos. Dentre eles, cita os terraços marinhos pleistocênicos e holocênicos.

O processo de uso e ocupação do terraço marinho holocênico pode representar sérios riscos quanto ao balanço hidrodinâmico dos sedimentos inconsolidados. A área estudada apresenta em alguns trechos casas de veraneio com forte densidade demográfica, como é o caso da Praia de Gaibu, Enseada dos Corais, Pedra de Xaréu e Itapoama, inclusive a zona de berma. Entretanto, a Praia do Paiva apresenta um contraposto em relação a essa densidade, resta-se salientar o projeto audacioso para essa praia em nome do desenvolvimento, a construção dos resorts.

De acordo com Carvalho (2003), o crescimento populacional e conseqüentemente, a ocupação urbana desordenada da faixa costeira das praias citadas com a alta densidade demográfica, aumenta a pressão sobre o território, levando à degradação deste, e de outros ecossistemas litorâneos interligados, como os recifes, estuários, restingas, campos de dunas, entre outros, que têm a função de proteger a costa.

Em áreas específicas como nas margens do rio Jaboatão, pode-se também identificar a presença de depósitos flúvio-lagunares. Tais regiões, segundo Bittencourt (1979), são consideradas sedimentos de origem lagunar, provenientes do afogamento da região no decorrer da última transgressão, sobretudo nas depressões existentes e, posteriormente, alimentadas pela ação fluvial da regressão subseqüente.

Associada às demais unidades, os depósitos de praia representam conforme Filho (2004), uma estreita faixa da praia atual, caracterizando a parte mais distal da planície costeira, sendo representados por areias quartzosas. Constituindo na maior parte da região foco de estudo, praias estreitas de baixa declividade, à exceção a Praia de Gaibu, formadas predominantemente por areias quartzosas bem selecionadas. 
A forma de tal seleção se dá face ao baixo grau de descaracterização de gênese antrópica em grande parte do trecho estudado. Podendo estas, em função da pressão e especulação imobiliária, alimentada pela indústria do turismo, ser em pouco tempo completamente alteradas, desencadeando, assim, processos de desestabilização num curto espaço de tempo, sobretudo em áreas consideradas mais frágeis como zonas estuarinas.

Constantemente se observa a ocupação muitas vezes desordenada, vindo a acarretar graves problemas de usos e conflitos, de erosão marinha acelerada, por exemplo. Segundo Pereira et al. (2003), 70\% da zona costeira do Estado de Pernambuco apresenta atualmente algum problema devido à erosão marinha, não podendo deixar de mensurar a ação antropogênica, principalmente pelo processo de ocupação intenso e desordenado destas áreas e a forma como foi tratada pela engenharia costeira nas bases de estruturas duras. A escolha da área a ser estudada representa em sua grande maioria as questões acima descritas. Esses impactos podem ser percebidos na área em questão versados por diversos fatores, proporcionando impactos muitas vezes de caráter irreversível à natureza e à sociedade.

\section{MATERIAIS E MÉTODOS}

Para obtenção dos dados realizou-se uma revista bibliográfica, análise de fotografias aéreas e revisões com base no Google Earth. Por razões didáticas, a área de estudo foi dividida: 1flecha e sistema de drenagem dos rios Jaboatão e Pirapama, que correspondem à praia do Paiva e Itapoama e 2 - materializa a praia de Pedra de Xaréu, Enseada dos Corais e Gaibu, com a restinga incorporada à zona costeira.

Analisaram-se amostras de água para verificação dos parâmetros de qualidade como: vegetação, poluição por esgotos, resíduos sólidos, pH, OD, DBO, coliformes termotolerantes, qualidade e risco de salinidade. Somando-se a esses dados, foram avaliados os índices de pluviometria dos anos referentes a 2007 e 2008.

De importância imprescindível, o método de análise para indicadores ambientais tem como referência os sociais, culturais e econômicos. Justificando como dados para uma análise sistemática holística das restingas e as sucessivas formações recentes, além dos processos reativos à erosão das praias. 
Diante das análises qualitativas e quantitativas, as entrevistas com a população mais antiga, questionários e a forma de vida dessa população serviram de indicadores ao quadro social nos pontos de maior densidade da população.

\section{RESULTADOS}

Do ponto de vista hidrográfico, a área da pesquisa é drenada pelas bacias dos rios Jaboatão e Pirapama. O encontro desses rios forma a área estuarina de Barra das Jangadas e juntos ocupam 128,4 km². O estuário apresenta-se em forma de " $\mathrm{S}$ " alongado (Figura 01), com largura variando de 200 a 250 metros de comprimento, em linha reta, de cerca de 2.500 metros. Visualiza-se na Figura 02 a flecha da praia do Paiva e área estuarina do rio Jaboatão.

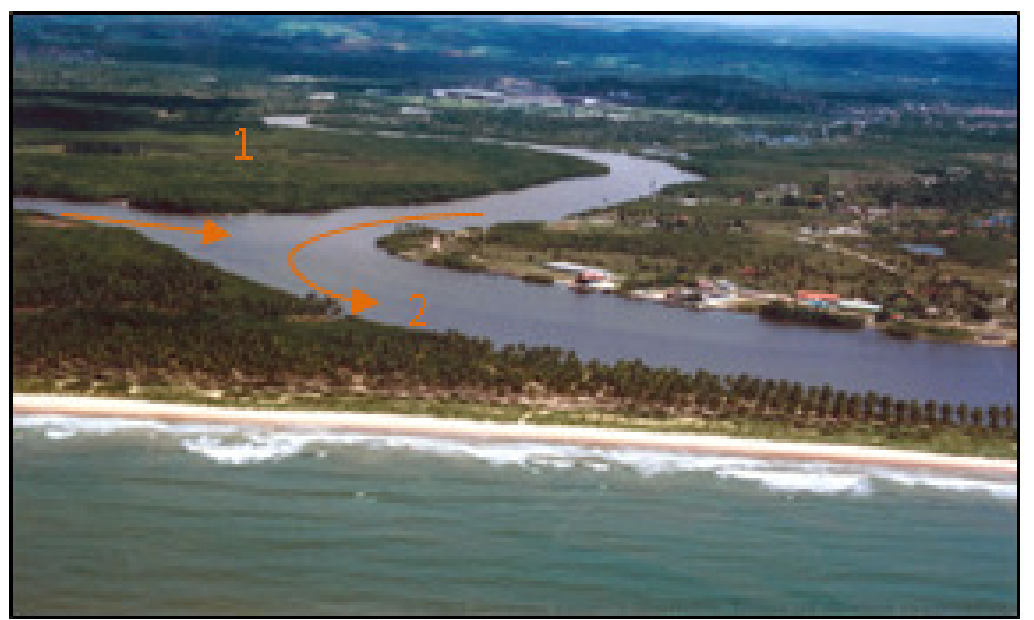

Figura 01: Vista da confluência do rio Pirapama (1) com o Jaboatão (2).

Fonte: Ricardo V. Monteiro. 2008.

Devido a acondicionamentos estruturais (adaptação à linha de falhas), o Pirapama muda seu percurso várias vezes entre a nascente e o início da Planície Costeira, que percorre no sentido geral oeste-leste até a altura da praia do Paiva. Neste ponto, inflete para norte, encontrando mais adiante, o rio Jaboatão. A partir dali, percorrem juntos 2,5 km, até a desembocadura em Barra das Jangadas. No trecho entre Camaçari e o rio Jaboatão, à retaguarda da praia e da restinga do Paiva, encontra-se o manguezal do rio Pirapama e parte daquele do rio Jaboatão. 


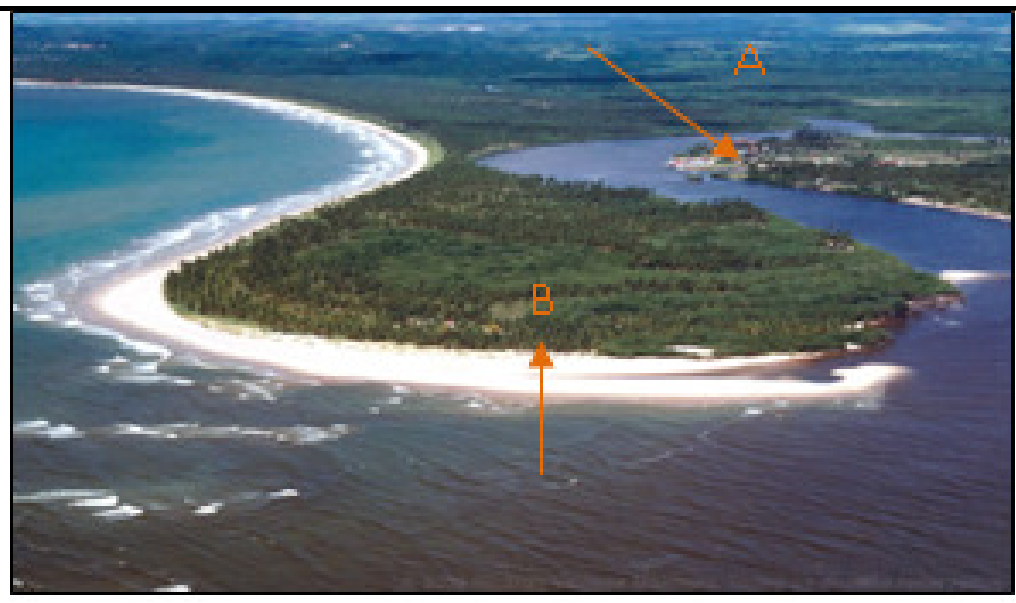

Figura 02: Área estuarina do Jaboatão (A) com a flecha da praia do Paiva (B). Fonte: Ricardo V. Monteiro. 2008.

Restinga é designada por Cristofoletti (1980) como uma barreira ou cordão litorâneo com base em formas arenosas depositadas paralelamente à praia. Mais recentemente, Guerra (1987), contribuindo aos estudos das restingas, refere-se a uma ilha alargada, podendo ser uma língua de areia depositada paralelamente ao litoral, que se deve às águas oceânicas. Oliveira (1998) define restinga como uma elevação arenosa, larga, resultado do processo de sedimentação de origem flúvio-marinha ou marinha, depositada paralelamente e próxima à linha de costa. Situada acima do nível do mar durante a maré alta.

A forma de transporte da deposição dos sedimentos não define uma restinga até que não se cumpra a última condição, por conseguinte, a restinga pode formar parte de um antigo litoral como no caso a referência pode ser feita às praias de Gaibu, Enseada dos Corais e Pedra de Xaréu (Figura 03), ou atualmente convertido em costa e constituir uma forma de litoral atual como exemplo a praia de Itapoama e Paiva (Figura 04).

Entretanto, a restinga na sua gênese, obedecendo à sua hidrodinâmica, pode apresentar várias formas. Tais como ilha de restinga (exemplo: ilha da Coroa do Avião), lagoa de restinga (exemplo: Lagoa Olho d’Água), esporão, tômbolo, cauda de cometa e flecha. Dentro da morfologia produzida pela hidrodinâmica marinha. A área de pesquisa contempla a planície como já foi citado anteriormente, a flecha constituída pelas praias do Paiva e Itapoama, (Figura 04) e no entorno espacial desse trabalho, a lagoa Olho d’Água (Figura 05). 


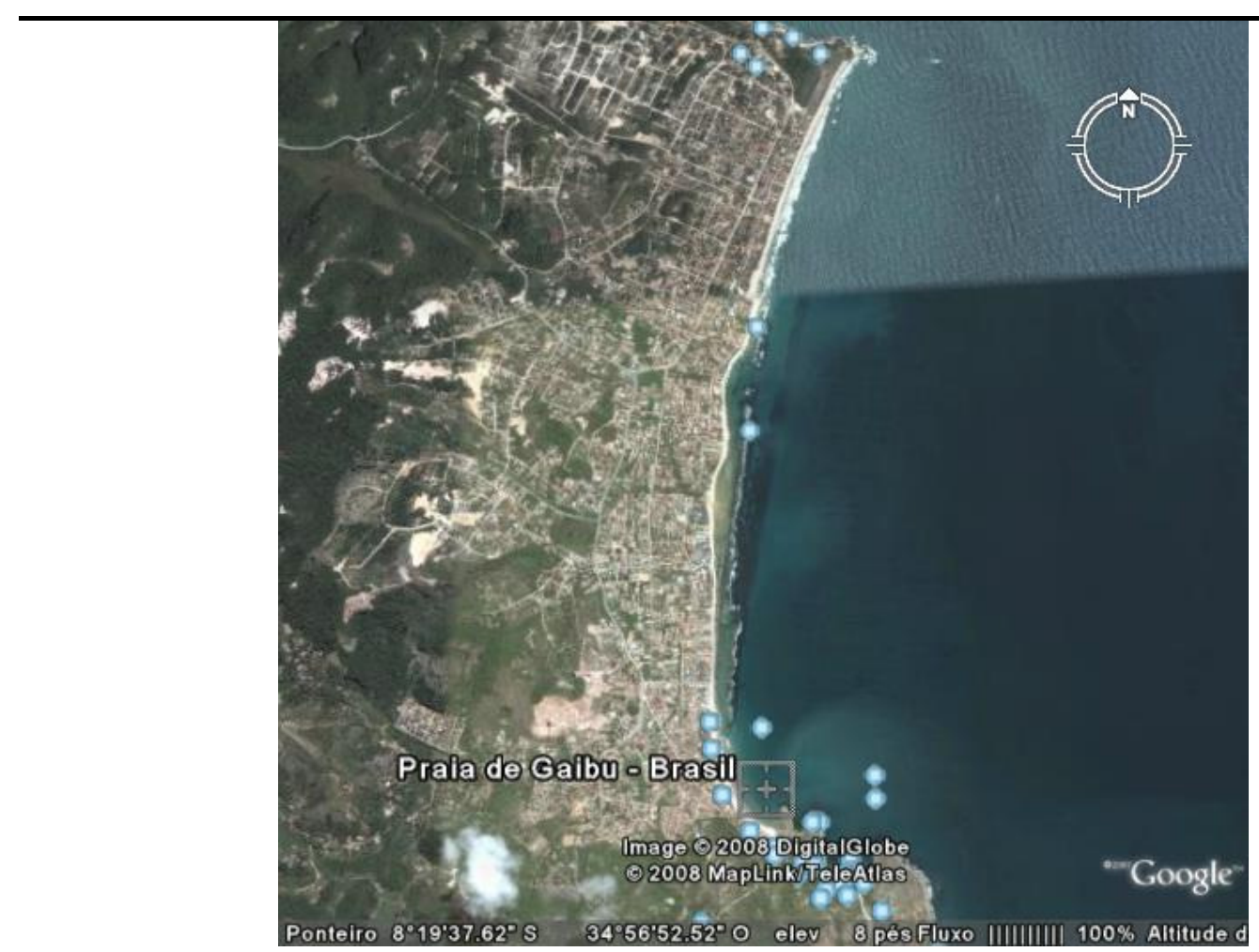

Figura 03: Planície de restinga das praias de Gaibu, Enseada dos Corais, Pedra de Xaréu.

Fonte, Google Earth. 2008.

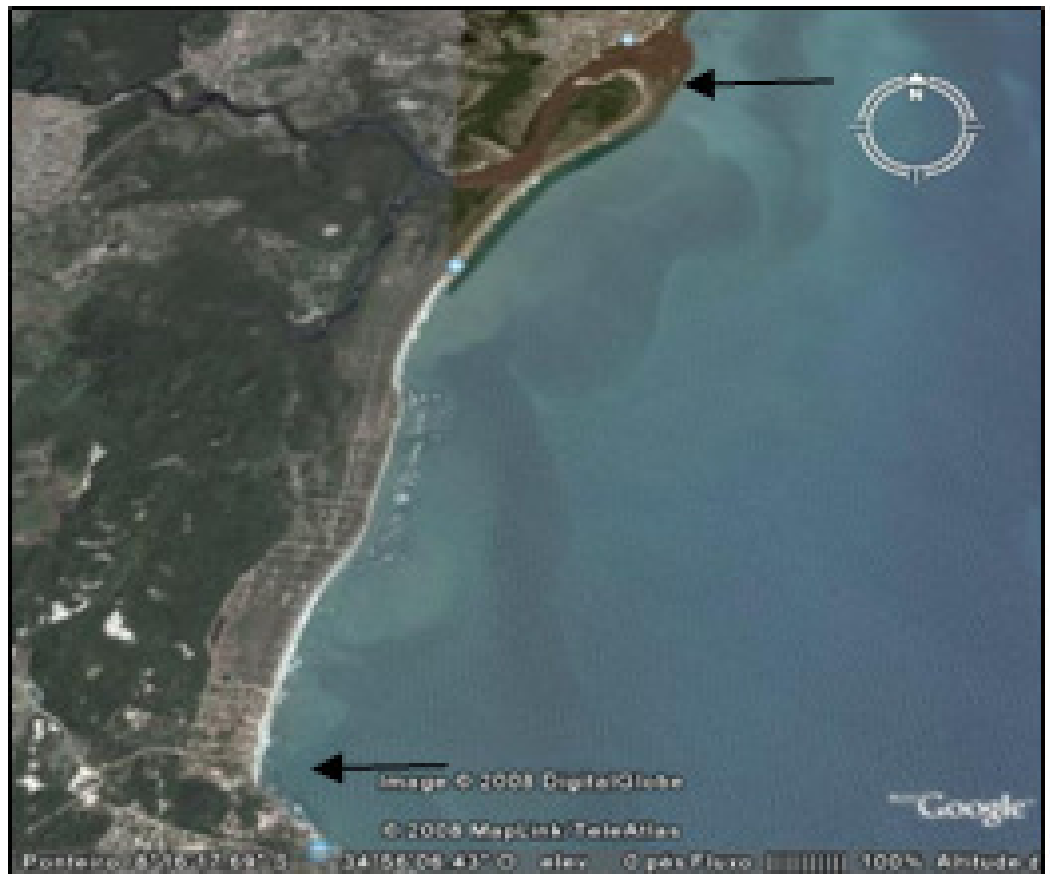

Figura 04: Flecha de restinga, praia do Paiva e Itapoama sentido N-S, representado pelas setas. Fonte: Google Earth, 2008. 


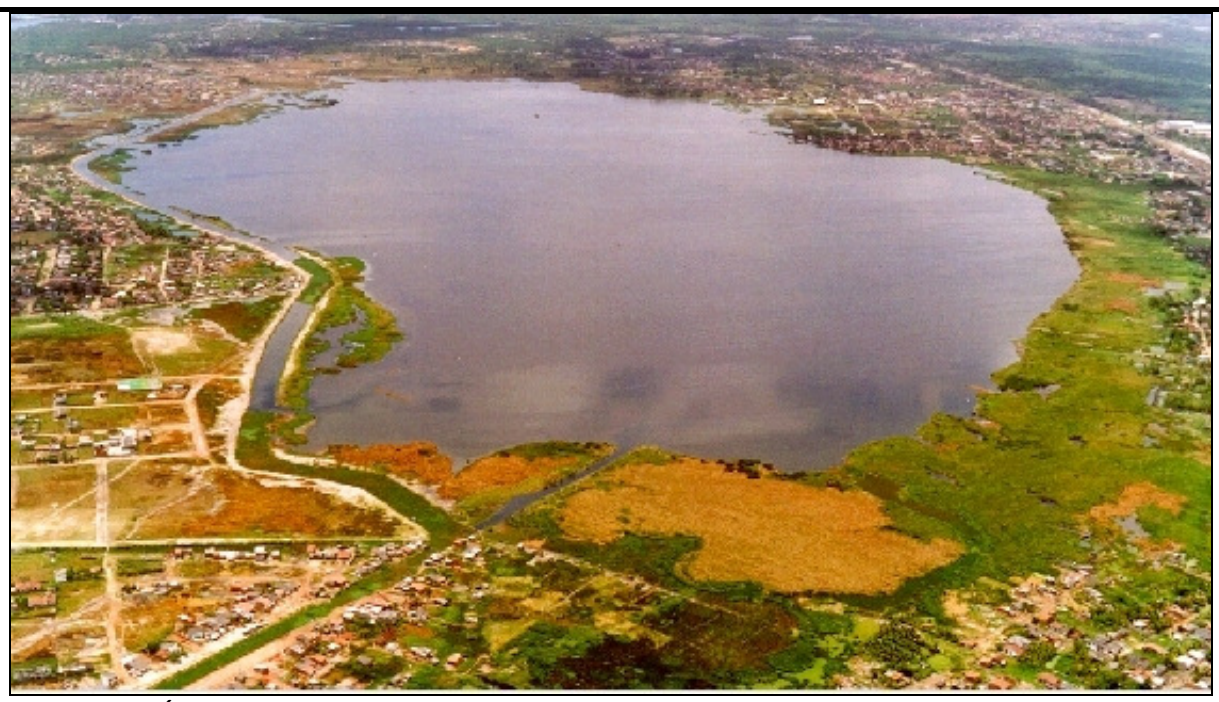

Figura 05: Lagoa Olho d’Água.

Fonte: Secretaria do Meio Ambiente, Jaboatão dos Guararapes. 2007.

O clima é As', pseudo-tropical com chuvas de outono e inverno resultante da massa Polar Atlântica e da Convergência Intertropical. Verifica-se nos índices pluviométricos como um fator preponderante à retroalimentação do curso inferior do sistema de drenagem dos rios Jaboatão e Pirapama. Entretanto, no que concerne à fitogeografia da área, a mesma está mais em conseqüência edáfica e de salinidade do que climática, como a vegetação dos campos de restingas. O mesmo não acontecendo com a mata de restinga, pois já existe a serrapilheira que se vê umedecida pelos índices pluviométricos, conseqüentemente realimentada pela ação das bactérias nas folhas, nos caules, nos galhos, e por fim na fauna. Os solos de natureza distrófica, constituído de areias quartzosas direcionam a água da chuva à inluviar através das faces intersticiais dos sedimentos. As plantas sofrem seca fisiológica, gerando uma sucessão de cactáceas, bromeliáceas, agaviáceas e o cajueiro vivendo em seu clímax.

A análise da pluviometria (Gráfico 01) para o ano de 2007 lê-se a seguir em dois momentos. O momento da média anual e histórica. Em se tratando da análise da média anual, observase o mês de maior índice pluviométrico o de junho, atingindo $429 \mathrm{~mm}$, fato perfeitamente justificado, pois é o momento da estação das chuvas. Enquanto o mês de julho representa o índice médio histórico também vivendo a sua maximização com $344 \mathrm{~mm}$. As mínimas da média mensal pontuaram-se para o mês de outubro com a ausência de precipitação, e a menor média histórica de $41 \mathrm{~mm}$ em novembro. Conferindo $1.940 \mathrm{~mm}$ anuais de precipitação no ano de 2007. Desse somatório, a média mensal gira em torno de $162 \mathrm{~mm}$. 0 somatório da média anual histórica corresponde a $2.110 \mathrm{~mm}$ e a média mensal história é de 
$176 \mathrm{~mm}$.

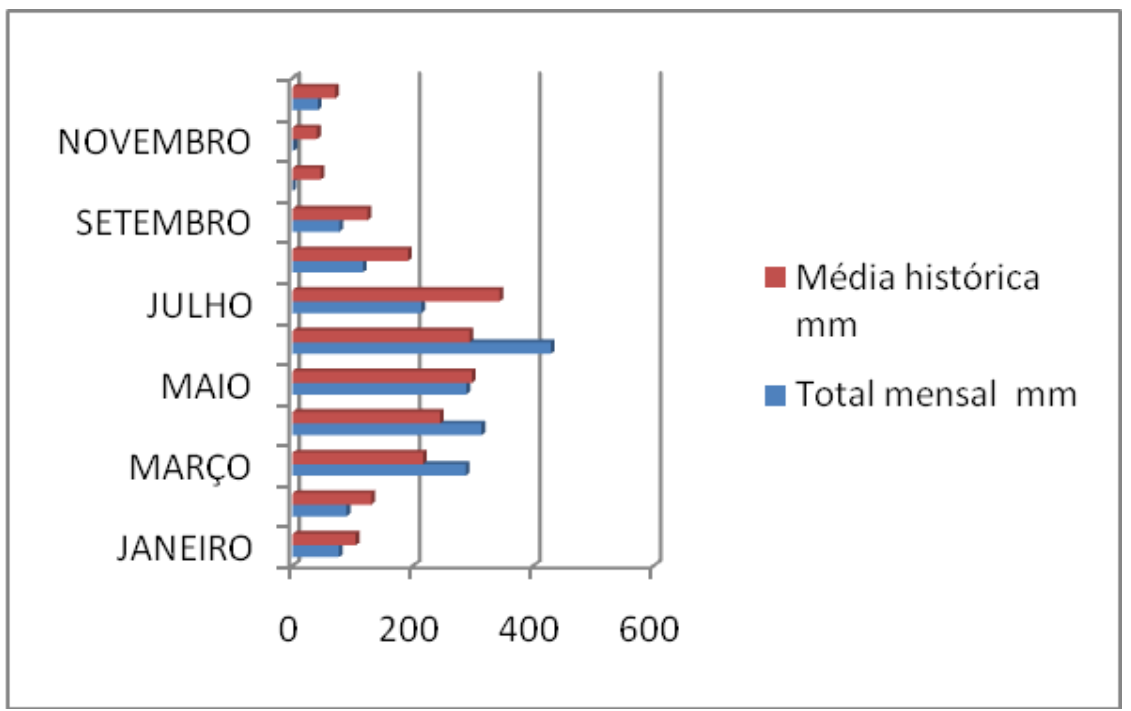

Gráfico 01: Índice pluviométrico das médias mensais e históricas. Estação Cabo de Santo Agostinho. Fonte: Os Autores com base de dados do ITEP/LAMEPE. 2007.

Os dados pluviométricos apresentam como indicadores de um alto índice pluviométrico, prestando-se para alimentação do geossistema hidrológico, constituído pelo sistema de drenagem a morfologia dos mangues e a mata de restinga. Nos momentos geradores de um maior fluxo hídrico da drenagem exorreica, a mesmas espraia-se em uma carga sedimentar muito mais elevada, gerando um quantitativo de sedimentos vindo a intensificar o surgimento de barras na área estuarina do rio Jaboatão (Figura 06), sedimentos esses que passam a ser interceptados pela barreira hidráulica do próprio rio atuando sobre a corrente de deriva litorânea; essa se vê interceptada e inicia o processo de deposição desses sedimentos sendo um dos fatores do surgimento dessas barras. Fato que vem a indicar o provável crescimento da flecha do Paiva.

O levantamento estabelecido não suscitou a importância da forma de degradação do sistema Jaboatão-Pirapama. Todavia, são tantos os fatores que o degradam, passando a ser um foco de fundamental importância às análises de um ponto de estação de coleta de água do referido rio. Justifica-se esse ponto, por ser a última estação no sentido montante-jusante (Estação JB-75-Pontezinha), coletado os dados através da CPRH (2007), quando se tem oportunidade de fazer uma análise dos impactos sofridos pelo devido sistema, constatandose na Tabela 01. 


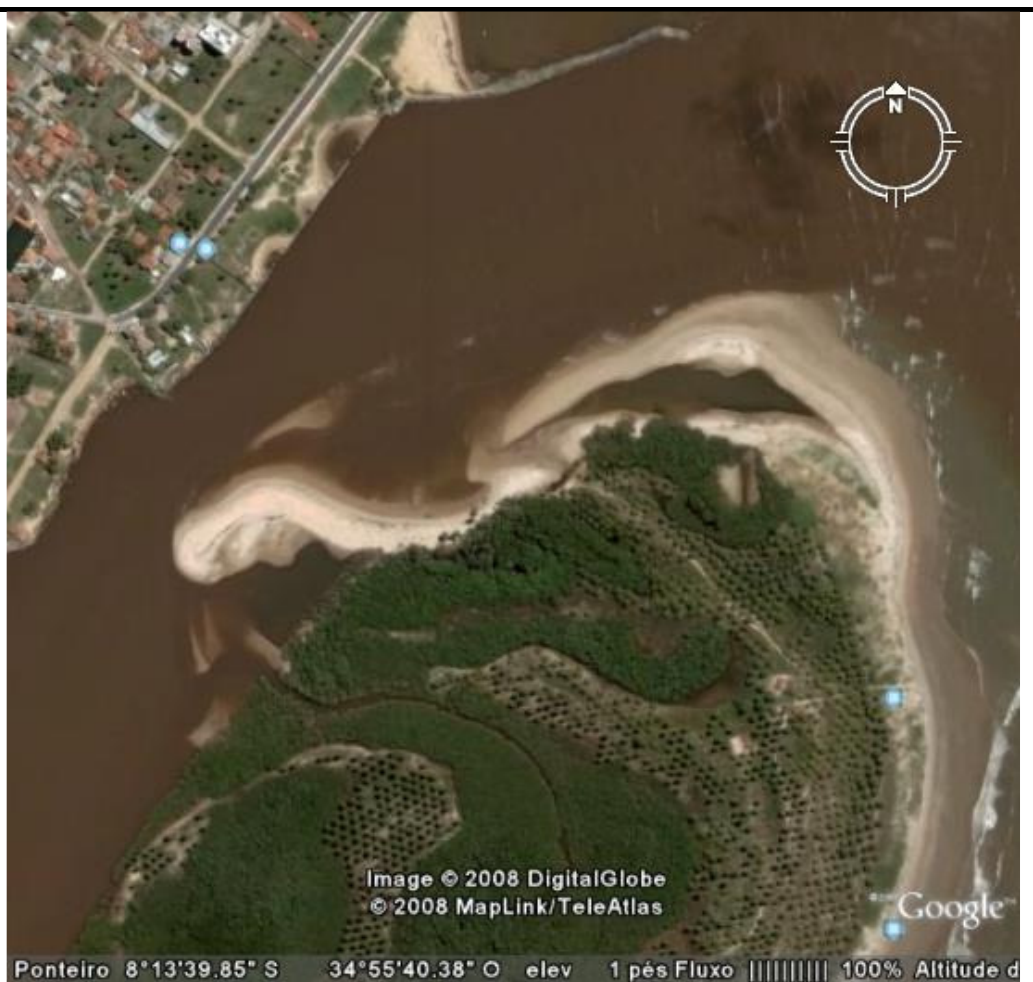

Figura 06: Foz do Rio Jaboatão em processo de crescimento como fase inicial a presença e barras.

Fonte: Google Earth. 2008.

\begin{tabular}{|c|c|c|c|c|c|c|c|}
\hline \multirow{3}{*}{ Parâmetro } & \multirow{3}{*}{ Unid. } & \multicolumn{6}{|c|}{ Data e Hora das Coletas } \\
\hline & & $10 / 01$ & 01/03 & 03/05 & $05 / 07$ & $13 / 09$ & $06 / 11$ \\
\hline & & $12: 45$ & $12: 40$ & $12: 00$ & $11: 40$ & $11: 50$ & $12: 05$ \\
\hline Aspecto da água & - & $\mathrm{T}$ & $\mathrm{T}$ & $\mathrm{T}$ & $\mathrm{T}$ & $\mathrm{T}$ & $\mathrm{L}$ \\
\hline Materiais & - & $A$ & $A$ & $A$ & $P$ & $P$ & $A$ \\
\hline Flutuantes & & & & & & & \\
\hline Condições do & - & ENS & ENS & ENC & ENS & ENS & ENS \\
\hline Tempo & & & & & & & \\
\hline Resíduo sólido & - & $A$ & $A$ & $A$ & $P$ & $A$ & $A$ \\
\hline Temperatura & $\stackrel{\circ}{C}$ & 29 & 27 & 27 & 25 & 25 & 28 \\
\hline $\mathrm{pH}$ & - & 6,8 & 6,8 & 6,6 & 6,9 & 6,8 & 6,9 \\
\hline OD & $\mathrm{mg} / \mathrm{L}$ & $\leq 0,5$ & $\underline{0,0}$ & $\leq 0,5$ & $\underline{0,9}$ & $\underline{1,2}$ & $\underline{1,0}$ \\
\hline DBO & $\mathrm{mg} / \mathrm{L}$ & $\overline{7,8}$ & $\overline{9,1}$ & $\underline{5,1}$ & $\overline{<0,5}$ & $\underline{6,3}$ & $\overline{<0,5}$ \\
\hline Coliformes & NMP/ & $\geq 16000$ & - & 28000 & - & 2200 & - \\
\hline Termotolerantes & $100 \mathrm{ml}$ & $\underline{\mathbf{0}}$ & & & & & \\
\hline Salinidade & $0 / 00$ & 0,2 & 0,3 & 0,1 & 0,3 & 0,2 & 0,6 \\
\hline
\end{tabular}

Tabela 01: Monitoramento da Estação JB-75 - Rio Jaboatão/Pontezinha.

Fonte: CPRH, 2007.

LEGENDA: Classe na CONAMA 357/05. L=Límpido, T=Turvo, A=Ausente, P=Presente, VE=Esparsa, VI=Intensa, ENS=Ensolarado, ENC=Encoberto; Avaliação de qualidade: $N C=$ não comprometida, $P C=$ pouco comprometida, $\mathrm{MC}=$ moderadamente comprometida, $\mathrm{P}=$ poluída e $\mathrm{MP}=$ muito poluída; Risco de salinidade do solo: $\mathrm{B}=$ baixo, $\mathrm{M}=$ médio, $\mathrm{A}=$ alto, $\mathrm{MA}=$ muito alto.

O parâmetro aspecto da água foi analisado do dia 10/01/2007 a 06/11/2007, de forma bimestral em horários entre $11 \mathrm{~h} 40$ e $12 \mathrm{~h} 45$, visualizando-se que de 06 amostras, o aspecto 
da água permaneceu turvo em 05 e em 01 límpido. Partindo desta primeira unidade, passa a indícios de um rio que flui de forma poluída; os materiais flutuantes analisados, os resultados indicam sua ausência em 04 coletas e em 02 momentos a presença dos mesmos. Provavelmente a ausência maior de material flutuante é por ter sido analisado em dias onde não ocorreram chuvas à montante do rio; quanto às condições do tempo, em apenas 01 coleta apresentou-se encoberto, fato que vem explicar até a unidade analisada anteriormente; os resíduos sólidos diante dos dados fornecidos apresentam-se somente em 01 coleta, as demais com a ausência de resíduos; no que se refere às temperaturas aferidas, o menor índice (25으) foi assinalado exatamente no mês de julho, momento da estação chuvosa; as temperaturas mais elevadas foram obtidas na estação as secas, variando entre $270 \mathrm{C}$ e $29 \circ \mathrm{C}$ e a média da temperatura aferida foi de $270 \mathrm{C}$. As temperaturas da água refletem de forma consistente as médias de temperatura da atmosfera.

Para os parâmetros químicos de qualidade da água, o índice de $\mathrm{pH}$ é considerado como variável ambiental de grande importância. Vendo-se, no entanto, que é uma das variáveis mais difíceis de interpretação. A resolução do CONAMA № 357/2005 estabelece para o pH em águas doces classe 2, o valor entre 6,0 e 9,0 e para as salobras e salinas classe 1, pH entre 6,5 e 8,5. Nas coletas realizadas, o pH sofre variações entre 6,6 e 6,9, podendo ser enquadrada na classe das águas salobras, classe 1 , sendo considerado de $\mathrm{pH}$ ácido, por estar abaixo de 7,0. A Resolução CONAMA №357/2005 estabelece o valor limite de $6 \mathrm{mg} / \mathrm{LO}_{2}$ para o oxigênio dissolvido (OD) das águas salobras classe 1. Nas amostras coletadas, todas estiveram fora das exigências do padrão do CONAMA com índice variando de $0,0,<0,5,<0,5$, 0,9, 1,0 e 1,2. A Resolução CONAMA №357/2005 em vigor realizou substituição não estabelecendo a Resolução №20/1986 para as águas salobras, a necessidade de análise dos parâmetros de DBO, sendo, portanto, substituído por carbono orgânico total. Todavia, a pesquisa viu de interesse a análise de DBO, pois a mesma reporta a um estudo que constrói o escopo do sistema fluvial em estudo. A Resolução vigente estabelece valores de DBO para as águas salobras e salinas em $5 \mathrm{mg} / \mathrm{LO}_{2}$, visualizando os dados, observa-se que em 02 coletas os valores foram $<0,5 \mathrm{mg} / \mathrm{LO}_{2}$, correspondendo às exigências do CONAMA.

Entretanto, 04 análises superaram as estabelecidas por esse órgão indicando uma alta demanda bioquímica de oxigênio; o parâmetro coliformes termotolerantes apresenta índices em NMP/ 100ml superando aos níveis de exigência, atingindo na área de trabalho valores muito altos como $160.000 \mathrm{NMP} / 100 \mathrm{ml}$ na coleta do mês de janeiro; a salinidade 
apresentou seu maior índice $(0,6)$ para o mês de novembro. Entretanto, os meses de março e julho, a salinidade foi pontuada em 0,3 e 0,2 , e 0,1 para os meses de janeiro e maio respectivamente. Como se observa, as estratificações das colunas d'água não foram significativas para o estudo no momento do ciclo das marés, apresentando-se com maior expressão nos meses de março e julho.

Em relação ao exposto, é mais uma pauta das relações dos processos a morte do sistema Jaboatão-Pirapama. Incorporadas às atividades industriais desenvolvidas na área como: a sucroalcooleira, química, alimentar, bebida, papel/papelão, matéria plástica, mecânica, material elétrico/comunicação, têxtil e vestuário, fármaco/veterinária, borracha, transporte e de calçados, somando-se ao déficit do sistema de esgotamento sanitário.

As áreas mais densamente povoadas estão concentradas nas praias de Gaibu, Enseada dos Corais, Pedra de Xaréu e Itapoama. A praia do Paiva está praticamente protegida em seu ecossistema com um número ínfimo de residências, mesmo porque nessa praia é dificultado o acesso por uma fiscalização constituída por uma barreira de vigilantes. Essa área pertence à família Brennand, que está com o pleito do macroprojeto da construção de resorts em consórcio com a construtora Odebrecht, inclusive projeto já aprovado pela CPRH ratificado por construção da ponte que interliga a praia do Paiva à praia de Barra das Jangadas. Essa mesma praia não vem sofrendo ação antropogênica direta, mas há indicativo de ações indiretas, sobretudo pelas praias que a antecedem e através do Porto de Suape.

Importante se faz a referência da destruição da mata primitiva pela cultura do coqueiro e hoje, toda essa zona de flecha deverá sofrer um processo de impermeabilização, passando a gerar problemas a uma área de estrutura frágil, constituída pelas areias quartzosas distróficas atualmente com alguns pontos já em processo de erosão das praias.

Das análises realizadas, foram de fundamental importância os trabalhos técnicos de campo, onde se pôde constatar vários impactos sofridos pela zona de pesquisa. Impactos por ação da natureza e por ação do homem. 


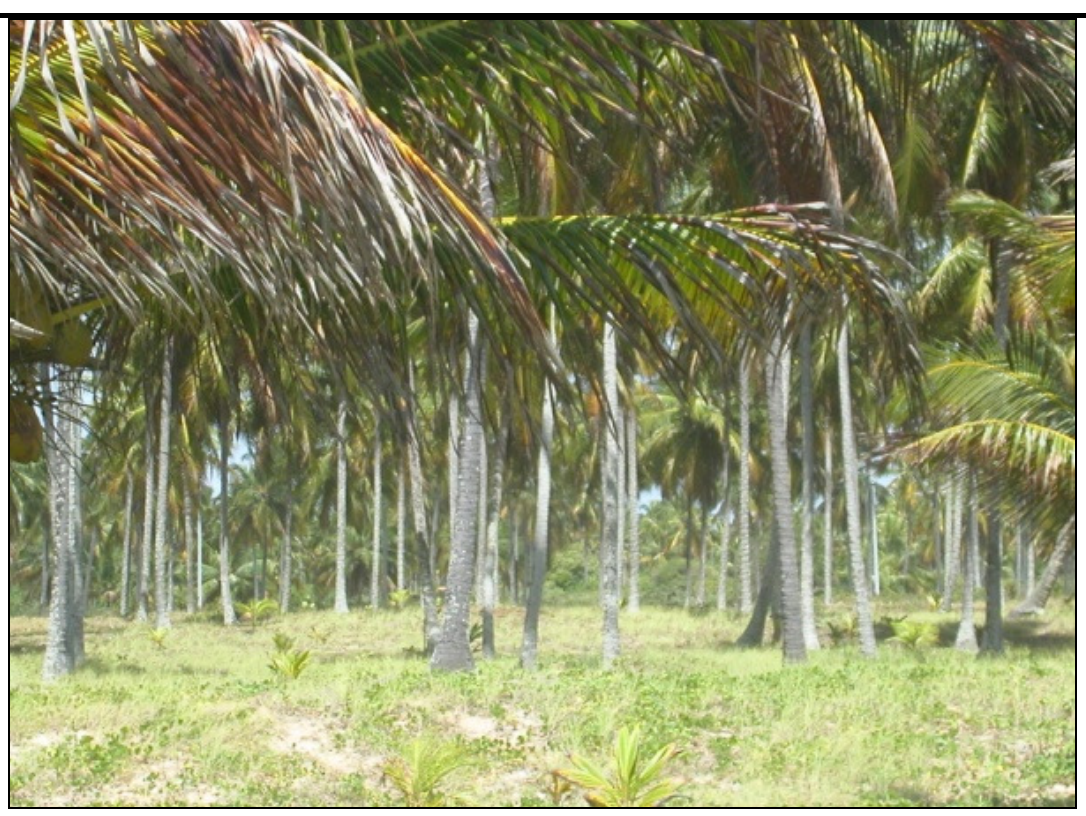

Figura 07: Cultura do coqueiro em detrimento da Flecha do Paiva.

Fonte: Oliveira, 2008.

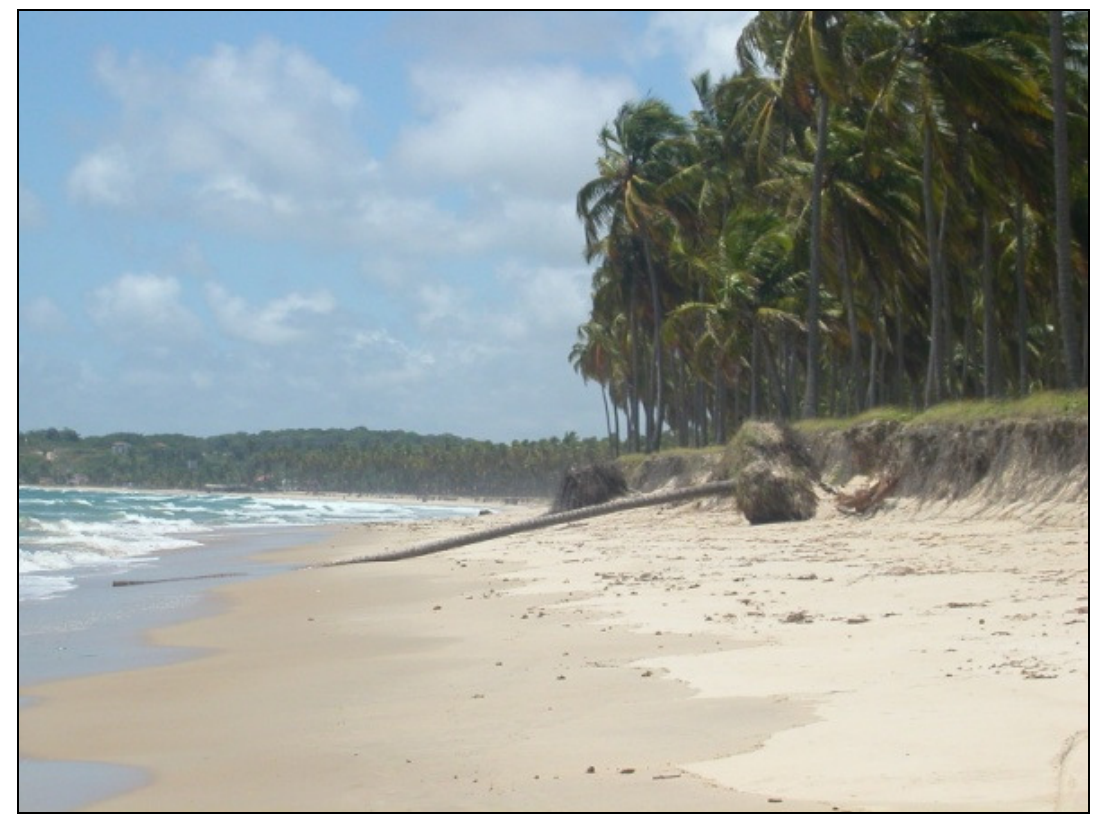

Figura 08: Foco do processo erosivo. Praia do Paiva.

Fonte: Oliveira. 2008.

\section{CONCLUSÕES}

$\mathrm{Na}$ área de flecha, de planície de restinga e de estuário do rio Jaboatão, existem áreas que merecem uma atenção emergencial em relação ao seu meio para minimização das ações geradoras de impactos ambientais que tem se caracterizado por processos naturais, e ações de caráter humano exercidas pela forma ou em via de ocupação do solo levando a insustentabilidade. 
As relações de uso e ocupação em especial as restingas onde se fixam as áreas urbanas desordenadas ou a área em processo de urbanização, conduzem a um estado crítico de manutenção da qualidade socioambiental. A relação sociedade-natureza, pautada na erosão das praias, na perspectiva de ocupação em área frágil da flecha do Paiva, na exclusão social, ultrapassa os limites da sustentabilidade.

Neste contexto, o trabalho enfatiza a prioridade de estudos sistemáticos da erosão das praias, da perda da cobertura natural bastante preservada na praia do Paiva e das variáveis indicadoras de poluição ambiental.

A partir dos resultados, foi identificada a planície de restinga a flecha do Paiva, que vai desde Itapoama até a praia do Paiva, área a ser urbanizada, drenada pelo sistema PirapamaJaboatão, cujas suas águas encontram-se em um processo de poluição profunda.

Fatos que anseiam por metas de solução preventiva aos futuros desastres causados na área sem a mínima preocupação de intervenção do poder público, que não cumpre e não fiscaliza as suas leis. A costa acumulativa em estudo deve ter como tônica de um olhar distraído a um olhar dirigido na eficácia de produzir mudanças ao desenvolvimento local e sustentável.

\section{REFERÊNCIAS BIBLIOGRÁFICAS}

BITTENCOURT, A.C.S.P., MARTINS, V.B., FLEXOR, J.M.(1979) Quaternary Marine Formattions of the Coast of the State of Bahia (Brazil). Atlas do Simpósio Internacional sobre a Evolução Costeira no Quaternário. São Paulo (SP). 232-253p.

CARVALHO, J.A.R. (2003) Classificação da Tipologia da Orla da Cidade de OLinda - PE: Delimitação e Caracterização do presente estado. In: II Congresso sobre Planejamento e Gestão Costeira dos Países de Expressão Portuguesa, 2003, Recife. Anais do II Congresso sobre Planejamento e Gestão Costeira dos Países de Expressão Portuguesa. Recife : UFPE.

CHRISTOFOLLETI, A.(1980) Geomorfologia. Ed. Edgard Blücher, São Paulo, 2ª Ed., 177 p. 1980

COBRA, R.T.Q. (1960) Geologia da Região do Cabo de Santo Agostinho. Belo Horizonte. Tese de Doutoramento. Faculdade de Filosofia/UFMG, 70 p. 
BRASIL. (2005) Congresso. Senado. "Resolução CONAMA No 357", 17 de Março de 2005.

Dispõe sobre a classificação dos corpos de água e diretrizes ambientais para o seu enquadramento e dá outras providências. Diário Oficial [da] Republica Federativa do Brasil, Poder Executivo, Brasília, DF.

GUERRA, A.T.,(1987) Dicionário Geológico Geomorfológico. Rio de Janeiro, 7ạ Ed., Fundação de Instituto Brasileiro de Geografia e Estatística, 372 p.

FILHO, J.D.M.,(2004) Aspectos Geoambientais entre as Praias do Paiva e Gaibu, Município do Cabo de Santo Agostinho (Litoral Sul de Pernambuco). Tese de Doutoramento. Curso de PósGraduação em Geociências/UFPE, 252p.

MANSO, V.A.V., LIMA FILHO, A.T.O., MEDEIROS, A.B., PEDROSA, F.J., MARTINS, M.H.A., MENEZES, M.O.B., CHAVES, N.S., KATER, K., COUTINHO, P.N., LIRA, A.R.A., \& OLIVEIRA, L. A. (1992) Macrozoneamento Costeiro do Litoral de Pernambuco - Folha Itamaracá (SB-25-Y-CVII). Convênio LGGM-DEMI_UFPE/CPRH. Relatório Técnico. 45p + 4 mapas em anexo.

MUEHE, D.(2001) Critérios morfodinâmicos para o estabelecimento de limites da orla costeira para fins de gerenciamento. Revista Brasileira de Geomorfologia 2 (1): 35-43.

OLIVEIRA, N.M.G.A. (1998) Problemas geomorfológicos - ambientales de las restingas y mangles en Pernambuco y Cuba. Tese de Doutoramento Ministério de Ciências y Tecnologia y Médio Ambiente. I.G.T. Academia de Ciências de Cuba. La Habana.

PEREIRA, L.C.C., JIMENEZ, J.A., MEDEIROS, C. COSTA, R. M. (2003) The influence of the environmental status of Casa Caiada and Rio Doce beaches (NE-Brazil) on beaches users. Ocean \& Coastal Management, 46:1011-1030. 